\title{
OPTIMAL CONTROL WITH THE DYNAMIC CHANGE OF THE STRUCTURE OF THE ROAD NETWORK
}

\author{
Zsuzsanna Bede, Tamás Péter \\ Dept of Control and Transport Automation, \\ Budapest University of Technology and Economics, Hungary
}

Submitted 27 September 2011; accepted 11 April 2012

\begin{abstract}
Optimization of traffic on a large public road network is a complex task. Reversible direction lane theory is an interesting and special method within this subject. This can completely support the fluctuation or alteration of main congested directions existing in the traffic dynamics (time of day, seasonal, etc.) on the existing road surfaces. In such case, certain subsystems of the main network cease to exist, and subsystems working with new connections take their place. This type of routing therefore changes the structure of the system 'in an optimal direction', but many practical and safety questions arise. The authors have examined the modelling of a Reversible Lane System (RLS) created based on a simple part of a road network, which is segmented into elements. Functions of each network element and contacts between them cease operating in the course of such change while new contacts and new function elements are activated instead. The article presents the mathematical modelling of the problem. It points out the fundamental questions of the structure change and exemplifies the above using a simple example. The authors studied a general mathematical model describing the RLS. They examined the availability of the optimal control in a sample network depending on the traffic density, using a new principle, which responds to the dynamic change of the structure of the network graph. It can be shown, that the results from the model are in harmony with the real traffic values based on measurements made in road traffic systems working with RLS.
\end{abstract}

Keywords: reversible lane system, road traffic, traffic control, optimal control, traffic lane, junction.

Reference to this paper should be made as follows: Bede, Z.; Péter, T. 2014. Optimal control with the dynamic change of the structure of the road network, Transport 29(1): 36-42. http://dx.doi.org/10.3846/16484142.2014.895959

\section{Introduction}

As congestion avoidance is of major importance, it receives a lot of attention, which results in a number of possible solutions. This includes technical devices that form a complicated technical system, e.g. real-time, traffic dependent on-board vehicles control.

The centralized nature of urban traffic characterizes the developing national economies which congestion takes shape in the morning towards the centre while in the afternoon roads leaving out of the city are more congested. In the afternoon traffic is less busy, and more distributed because of the different sizes of the destination areas and of the different working hours. Typically, with improving lifestyles, people move out of cities to commute daily from nearby towns. This process creates more commuters so traffic forms throughout larger destinations.

Taking advantage of the given vehicular traffic size of the directions differing in a moment of time, it would beneficial to create interchangeable direction lanes that would take the current traffic flow into consideration, and provide optimum room for both directions. Reversible lanes must be designed based on environmental and social demands of a location.

The principle of the most favoured innovations is the increased effective use of new and existing road networks, the homogenization of vehicle traffic, the increase in passengers in single vehicles (carpooling), or the use of public transportation. The general use of vehicles led to the formation of larger vehicular traffic size, which caused congestions. The use of reversible lanes was one of the primary methods of the last century used to handle peak period traffic flows, pioneered in the 1920's. Metal-based columns were initially used to delineate the temporary division between opposing traffic flows during the early period, and after 1950's the new traffic cones were deployed. The Reversible Lane System (RLS) has been used all over the World, the specificity

Corresponding author: Zsuzsanna Bede

E-mail: bede.zsuzsanna@mail.bme.hu 
of which lies in that it can increase the capacity of roads (Wolshon, Lambert 2006).

The optimization is realized by two methods:

1) Control based on the daily traffic. In this case, the vehicle flow happens in the direction of the probably bigger traffic on the section.

2) Model Predictive Control method (MPC) based on numerical optimization, in which the future values (seen on the finite time horizon and presumable discrete time) of the intervenor sign are determined through optimizing of the objective function in every discreet time step. The value of the objective function that can calculate the function of the intervenor sign and the initial state depends on the future states of the system.

\section{The Mathematical Modelling of RLS}

\subsection{List of Used Symbols}

$\alpha_{i j}-$ distribution rate;

$\beta_{i, j}$ - obstruction;

$\boldsymbol{K}(x, s), \boldsymbol{K}^{\text {inp }}(x, s), \boldsymbol{K}^{\text {ex }}(x, s)$ - connection matrices;

$L^{-1}$ - reciprocal of inner section lengths;

$l_{1}, l_{2}, \ldots, l_{n}$ - section lengths of inner section;

$p_{1}, p_{2}, \ldots, p_{m}-$ section lengths of each external section;

$s$ - state parameter in the external part of network;

$s_{1}(t), s_{2}(t), s_{3}(t), \ldots, s_{k}(t)$ - vehicle densities of each external section;

$x$ - state parameter of inner section;

$x_{1}(t), x_{2}(t), x_{3}(t), \ldots, x_{n}(t)-$ vehicle densities of each section;

$v_{i j}$ - transitional velocity from inner section $j$ to inner section $i$

$v_{i j}^{i n p}$ - transitional velocity from external section $j$ to inner section $i$.

\subsection{Mathematical Model Applied to this Solution of Problem}

In the model, as in reality, the geometry elements do not disappear naturally, but create a variable network as a result of their new function and their connection system. The descriptive mathematical network model is a positive Non-Linear (NL) dynamic system, and also important that it is a macroscopic model. The function of every element and the contacts between the elements cease in case of direction change in any part of the network, then new contacts and new functional elements are activated (Peter, Basset 2009; Peter Bokor 2010, 2011).

The elaborated model is in state space form where the states are vehicle densities on a particular lane and the dynamics is described by a NL state constrained positive system.

The first definition of positive systems was given by Luenberger (1979), that a positive system is a system in which the state variables are not negative. The majority of the of the analysed road traffic processes meet this requirement based on the original physical meaning of their states. Road traffic processes are usually described in the literature by setting up general linear systems of equations not exploiting the positive characteristics of the processes. We might think that the known properties of general linear systems are true in case of the positive systems as well, but they are not. The terms of controllability and observability of positive systems are not derivable from the known methods applied in general systems. The problem is particularly true when a nonnegative co-domain is required not only for the states, but for the control input sign too. Therefore, describing the road system processes as pure positive systems is not a trivial task from the control engineering point of view. The control task in this case means that the system must be controlled from a state to another so that the states remain non-negative values during the transitions too. The descriptions of the systems and controllability were given by Caccetta and Rumchev (2000), Farina and Rinaldi (2000) in systematizing works, and by Bacciotti (1983), Coxson and Shapiro (1987), Valcher (1996). According to Boothby (1982) and Sachkov (1997) regarding the real matrix $\boldsymbol{A}$ applied in control theory the following theorem holds: the system is positive if and only if the matrix $\boldsymbol{A}$ is a Metzler matrix, i.e. all of the elements not in the main diagonal are non-negative (the elements in the main diagonal may be arbitrary). In our case NL positive systems are examined.

The model is composed of an inner network of $n$ sections bounded by a closed curve $G$ and an external network of $m$ sections. In the model $x$ is the state-parameter vector of the inner sections and $s$ is the stateparameter vector of the external sections. The state of the latter is considered to be known based on measurements. The outer network is composed of sections, which are in direct (inflow or outflow) connection with an inner section.

The state equation of the original physical model is the following NL differential set of equations:

$$
\dot{x}=L^{-1} \cdot\left[\boldsymbol{K}(x(t), s(t)) \cdot x(t)+\boldsymbol{K}^{i n p}(x(t), s(t)) \cdot x(t)\right],
$$

where: $t \in \mathfrak{R}, x \in \mathfrak{R}^{n}, s \in \mathfrak{R}^{m}, L=\operatorname{diag}\left\{l_{1}, \ldots, l_{n}\right\}$ contains the lengths of the inner sections $\left(\forall l_{i}>0, i=1,2, \ldots, n\right)$, $K \in \mathfrak{R}^{n x n}, \boldsymbol{K}^{i n p} \in \mathfrak{R}^{n x m}$. In the model $\forall x_{i}(i=1,2, \ldots, n)$ and $s_{k}(k=1,2, \ldots, m)$ state-parameters are dimensionless densities and take values in the interval $[0,1]$.

Based on the following it is evident that $K$ is a Metzler matrix and $K^{i n p}$ is a positive matrix, to the effect that it does not contain negative elements.

The physical meaning of the elements $v_{i j}(i=1$, $2, \ldots, n ; j=1,2, \ldots, n)$ of matrix $K$ is velocity $(\mathrm{m} / \mathrm{s})$. In the case of $v_{i j}$ it means the transitional velocity from inner section $j$ to inner section $i(j \neq i)$ which is a nonnegative value. In the main diagonal $v_{j j}$ (which denotes the outflow velocities from inner section $j$ ) is the sum of outflow velocities to the inner and external sections in case of section $j$. These are non-positive values. To sum up: there are zeroes or negative values in the main diagonal of $\boldsymbol{K}$, every other element is 0 or positive, consequently, $\boldsymbol{K}$ is a Metzler matrix. 
The physical meaning of the elements $v_{i j}^{\text {inp }}(i=1,2$, $\ldots, n ; j=1,2, \ldots, m)$ of matrix $\boldsymbol{K}^{i n p}$ is velocity $(\mathrm{m} / \mathrm{s})$ as well. In the case of $v_{i j}^{\text {inp }}$ it means the transitional velocity from external section $j$ to inner section $i$, which is a non-negative value. Consequently, in the case of $\boldsymbol{K}^{\text {ex }}$ every element of the matrix is 0 or positive.

\subsection{The Contact Matrix of RLS, Control Signs and State-Parameters}

There are two traffic directions on the left side of Fig. 1, where the contacts of the sections are marked thickly. The examined sections are labelled with a circle in case of 1 st direction and with a square in case of 2 nd direction. Two kind of contact forms exist (Bede et al. 2010; Bede, Péter 2010; Péter et al. 2011):

1) Constant geometry contact: i.e. contact of $i$ and $j$. In this case the geometry contact remains in all traffic direction change, but what changes is the direction of course (in case of 1st direction: $i \rightarrow j$, in case of 2 nd direction: $j \rightarrow i$ ).

2) Contact depending on direction: i.e. in case of the 1 st direction contact of $j$ and $l$, in case of the 2 nd direction contact of $j$ and $k$. In this case the geometry contact depends on the traffic direction (in case of 1st direction: $j \rightarrow l$, in case of 2 nd direction: $j \rightarrow k$ ).

Two things must be enhanced: the contact between $i$ and $j$ elements and the direction of this transition, for example $\boldsymbol{K}_{i, j}$ element, if not equivalently 0 , shows that there is a contact and that $j$ works onto $i: j \rightarrow i$.

All such contacts remain invariant in the contact matrix, which does not affect the direction change!

The contacts, which are affected by the direction change, the contacts connected to 1 st and 2 nd direction close one another off! I.e. in the contact matrix, the contact may appear which is marked only with a square or with a circle in a certain time.

In case of a constant geometry contact: the contact is reflected onto a main diagonal as a result of the direction change $(i, j) \leftrightarrow(j, i)$.

There is no reflection in case of the contact connected to only a single direction. This contact appears in only one direction, for example $j \rightarrow k$.

Finally, this is very important, that the contact change does not happen at the same time in the contact matrix. The dissociation of the contacts happens in two steps.
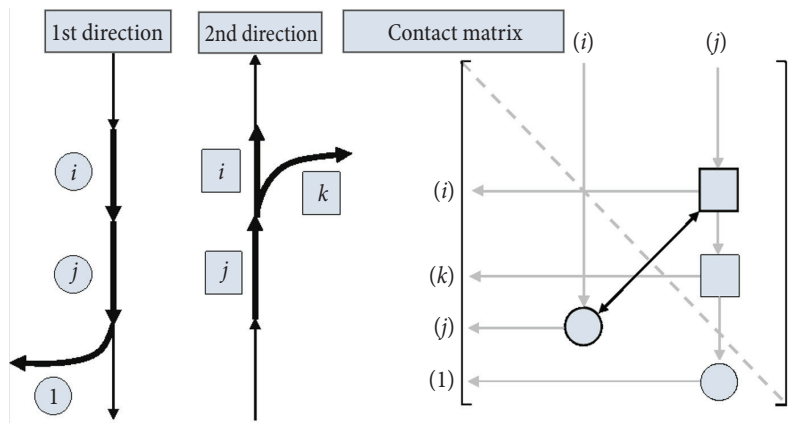

Fig. 1. Two traffic directions and the contact matrix (source: own elaboration)

\section{Example the Model of RLS}

The model is NL positive system with 12 degrees of freedom (Fig. 2), 7 external contacts where:

$-s_{1}, s_{4}, s_{5}$ are measured inputs, with $p_{1}, p_{4}, p_{5}$ section lengths;

$-s_{2}, s_{3}, s_{6}, s_{7}$ are measured outputs, with $p_{2}, p_{3}, p_{6}$, $p_{7}$ section lengths;

$-1,2, \ldots, 11$ are network sections characterized, with $x_{1}, x_{2}, \ldots, x_{11}$ state parameters and with $l_{1}$, $l_{2}, \ldots, l_{11}$ section lengths;

- 12 is reversible lane in both directions marked with $x_{12}$ state parameter and with $l_{12}$ section length.

Let us assume that:

- a morning peak is evolved in the section directed upwards from below. Section 3 often gets a red light as a result of the crossing railway traffic, because of this the section 2 and 1 get blocked;

- an afternoon peak is evolved in the section directed upside-down; at this time the vehicle density of section $s_{6}$ is overload, because of this section 9 often gets blocked as a result of this 8, too, and this influences 6 and onto 7 !

The obstruction is marked $\beta_{i, j}$ by transition through $j$ to $i(j \rightarrow i)$. Obstruction appears between the sections below, at the right side sections in the model:

$\beta_{2,1}:(1 \rightarrow 2) ; \beta_{3,2}:(2 \rightarrow 3) ; \beta_{4,2}:(2 \rightarrow 4) ; \beta_{4,5}:(4 \rightarrow 5)$

and at the left side sections:

$\beta_{8,6}:(6 \rightarrow 8) ; \beta_{9,8}:(8 \rightarrow 9) ; \beta_{10,8}:(8 \rightarrow 10) ; \beta_{11,10}:(10 \rightarrow 11)$.

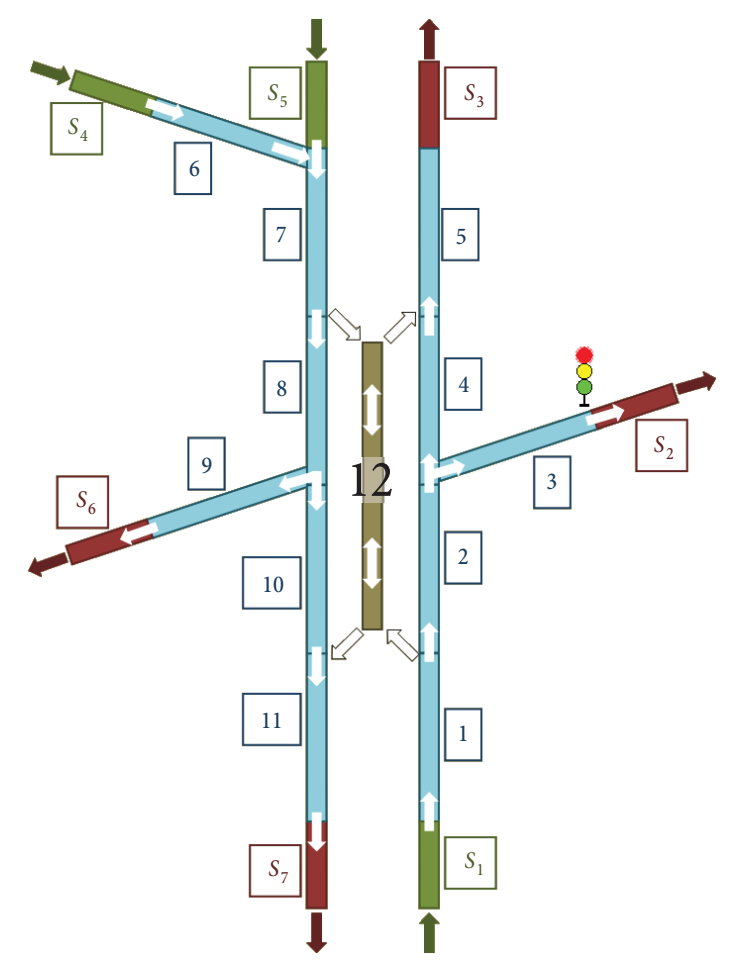

Fig. 2. Sample model, on model of RLS (source: own elaboration) 
The distribution rate is marked $\alpha_{i j}$ with passing through $j$ to $i(j \rightarrow i)$. A distribution rate appears between the sections below, at the right side sections in the model:

$$
\alpha_{12,1}:(1 \rightarrow 12), \alpha_{2,1}:(1 \rightarrow 2),
$$

where: $\alpha_{2,1}=1-\alpha_{12,1}$.

If section 12 is not used, $\alpha_{12,1}=0$, and $\alpha_{2,1}=1$, if it is used and supposed that $\alpha_{12,1}=0.45$ rate, and at this time $\alpha_{2,1}=0.55$. The survey of the rate is interestingly formed with the $2 \rightarrow 3$ transition. Let this be $\alpha_{3,2}$ : $(2 \rightarrow 3)$, if section 12 is not used, i.e. this means, that being in the section 2 wish to turn right in the above ratio. These drivers wish to turn right here when the section 12 works, because this is their route in the morning peak. The number of drivers in the section 2 is decreased by working of section 12 , according to a $\alpha_{2,1}$ factor.

Because of this transition from 2 onto 3: it is necessary to count with a $(2 \rightarrow 3): \alpha_{3,2} / \alpha_{2,1}$ rate, respectively, if in all cases the $\alpha_{12,1}$ rate is counted, the transition from 2 onto $4:(2 \rightarrow 3): \alpha_{3,2} /\left(1-\alpha_{12,1}\right)$ and $(2 \rightarrow 4): 1-\alpha_{3,2} /$ $\left(1-\alpha_{12,1}\right)$.

The same happens to the inscription of the distribution rates with the vehicles travelling from the other direction.

\section{Possible Applications in Hungary}

In Hungary, traffic lanes with changeable directions are mentioned as a sub-function of the integrated line regulation system (Wolshon, Lambert 2006).

In Hungary, this practice could be applied considering the EU goals aimed at improvement of traffic systems. Besides, it should be underlined that more advanced technological resources are available at present if compared to the first trials conducted in the U.S. Currently Hungary is in the period of continuously growing traffic flow which can be easily regulated with modern control systems.

With the use of reversible direction lanes one has to separate urban and highway traffic. At their design one also has to take into consideration whether the system will be used on existing or on a new road network. The former mentioned way is most common in urban, while the latter in highway planning. On highways, safety has to be provided at higher speeds so similar safety standards require more attention and input that can be easier realized with new developments (Čygas et al. 2009). There are cases where a wide area is available, but at a shorter section we are forced to decrease the width of the road. At this narrow width it is worth employing reversible direction lanes if it is demanded by vehicular traffic size. In short if vehicular traffic size varies greatly in both ways and this variance happens with changing traffic jam patterns between directions.

\subsection{Utilization on Highways}

The traffic flow of highways near cities is greater in the morning with the incoming, and in the afternoon with the outgoing flow. There can be differences in both directions near recreation areas seasonally. This change mostly shows in weekend traffic, or on long weekends with national holidays.

Even if only for a short time one would like to increase the number of lanes one has to make sure that with the increased section traffic, the end of the section can handle the increase without newer jams, meaning the network of roads after installation of the interchangeable lanes is able to handle such increases. Because of this reason in the planning of these lanes one also has to pay attention, to vehicle destinations to provide appropriate down channelling.

In case of a new concept it is worth planning the freeway with at least one reversible direction lane to save the costs of one lane, since it is important that instead of 6-lanes for example only 5-lanes have to be built. With this its usability is increased, however it is an expensive and complex task to solve the problem of routing the traffic on and off the reversible lane. It has to be thought through what length of freeway is worth saving on lanes. This train of thought is necessary in case of roads passing by historical sights, or existing freeway lane additions. An economic solution during new concepts or during additions could be to build one lane less (Berta, Török 2010). This way the traffic change of the inner lane could be needed as well, along with the change in traffic flow.

\section{Case Study: Common Stage of M1-M7}

One of the largest traffic in Budapest happens on the common part of the M1 and M7 motorways. In case of Reversible Lane it has to take care of the increased traffic.

Towards Pest this traffic can be conducted to Egér Road. This route has two lanes, but the exit ramp from the motorway has only one lane and the modification of this to double lanes would not demand for large investment. During the peak period hours the users of the exit ramp would have priority over the traffic of Egér Road. During non-peak hours the present formation would remain, consequently, the change would be signalled by LEDs. Fig. 3 shows the practical changing - direct or bending - of the lane on the mentioned road-section.

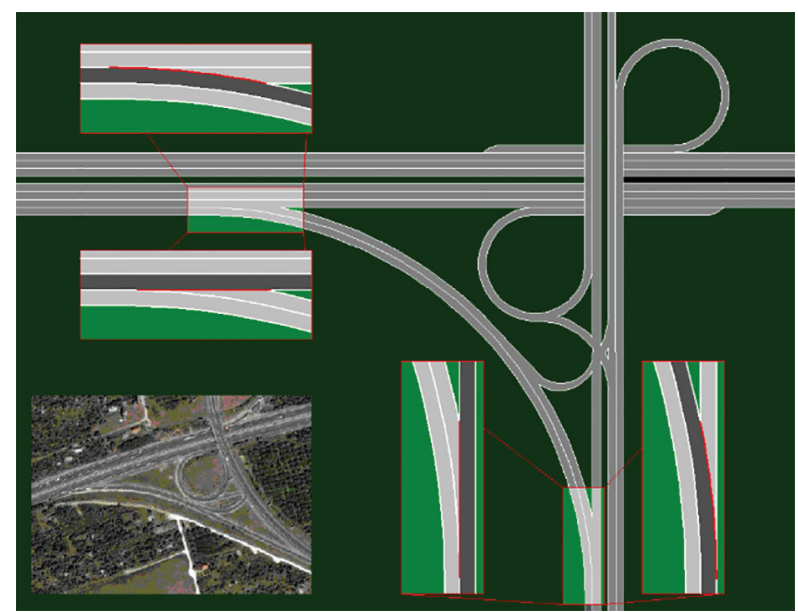

Fig. 3. Junction of common stage of M1-M7 and Egér Road (source: own elaboration) 


\subsection{Examples for Possible Urban Undertakings}

\section{Case study: Üllöi Road in Budapest}

The presentation of the system was chosen the Üllöi Road since this is the city's one radial main road (Figs 4 and 5). The bigger vehicle quantity moving towards the centre in the morning and moving outwards in the afternoon is typical of this section.

The other viewpoint of the designation was the geometry conditions. 3-lanes are available in both directions on the section between Ferenc Boulevard and Ecseri Road, these are constricted only 2-2 lanes on the overpass and on the section of Üllöi Road between Kálvin Square and Ferenc Boulevard. Like this if one takes away one lane from either direction, at least one lane still remains on the length of the full section.

The model was prepared from a map, i.e. it gave the length of the section proportionally, according to the re- ality. Firstly, the current state was modelled and then the direction of a lane from Kalvin Square to Ecseri Road was reversed in the morning hours. The arrival times was examined in the course of two kinds of simulations. One may make the undermentioned statement on the basis of the preliminary measurements: if the driving inwards in the morning peak time is helped with plus one lane, then the arrival time decreases by $50 \%$ on average and if one lane is taken away the opposite direction, then the arrival time increases at most 30\% (Fig. 6).

\section{Validation}

The validation of the mathematical model took place with the examination of the boulevard from the Petöfi Bridge to the Nyugati Square in Budapest (Bede, Péter 2010).

The simulated setting of signalling-lamp crossing corresponds with the values of the actual setting of the

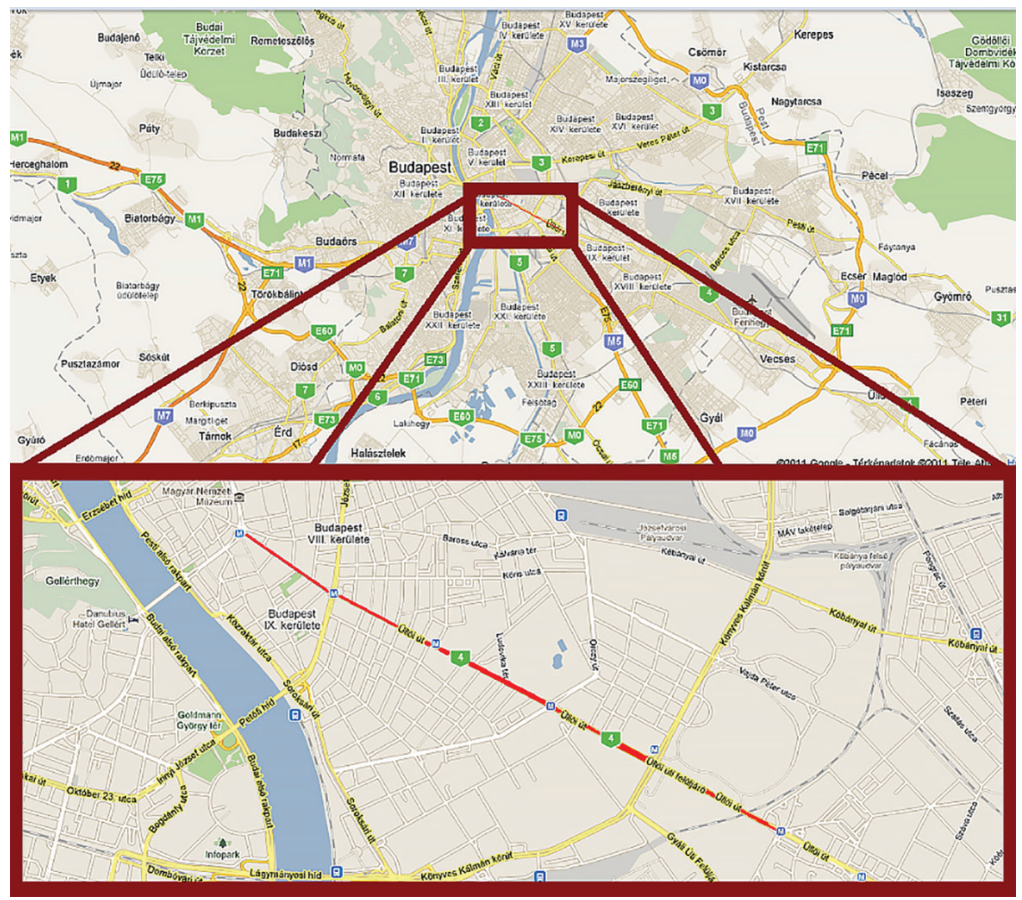

Fig. 4. Üllői Road, one radial main road of Budapest (source: own elaboration)

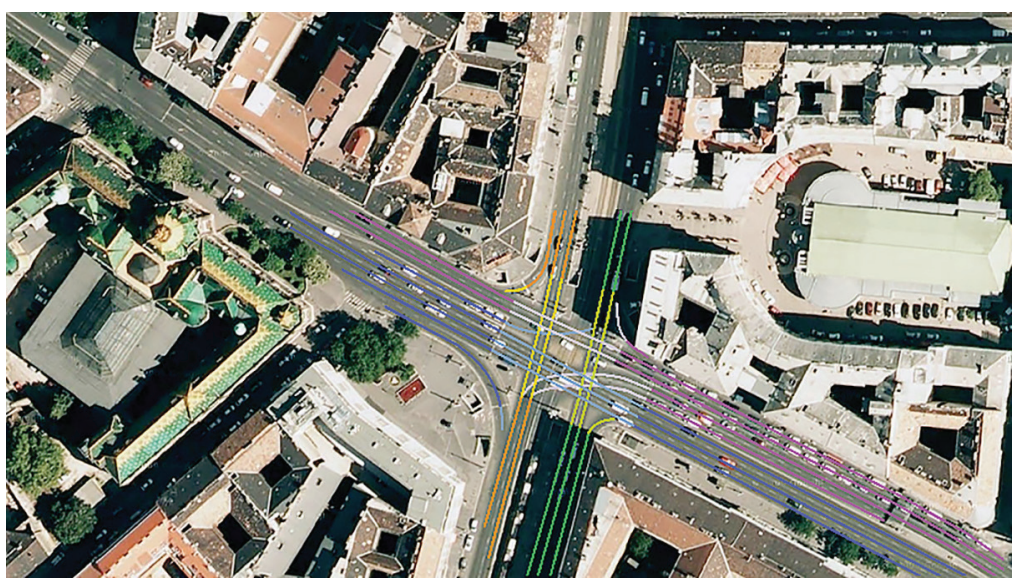

Fig. 5. Üllöi Road, one radial main road of Budapest (source: own elaboration) 


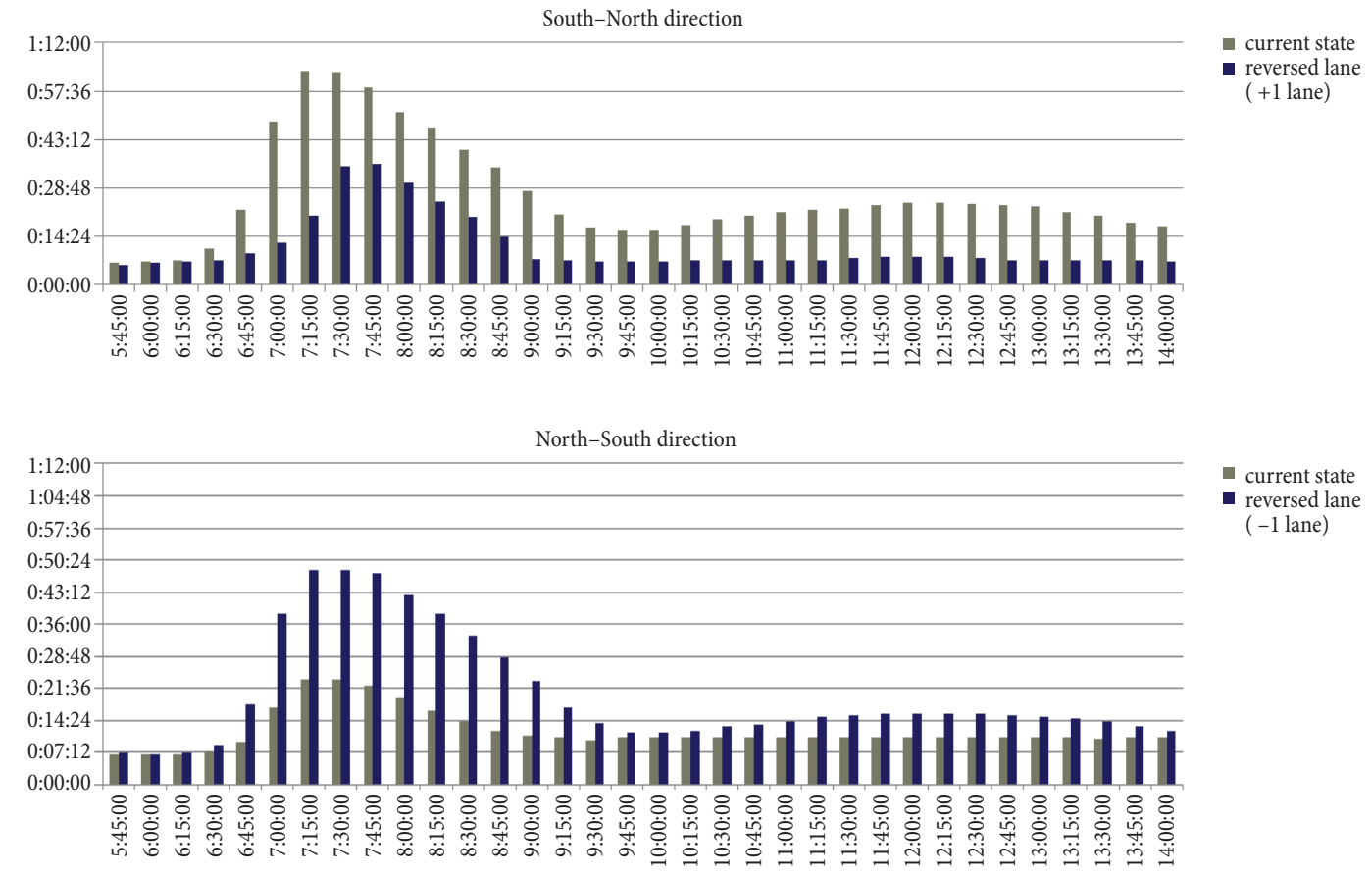

Fig. 6. Results of simulation of arrival times (source: own elaboration)

signalling-lamp, that are available for the Budapest University of Technology and Economics, Department of Control and Transport Automation. Traffic was counted on the three biggest junctions of the examined section.

In the course of the vehicle measurement the current position was fixed with GPS in every second. The velocity profiles derive from these data compared with the velocity profiles obtained from the simulation. The velocity distributions were compared with nonparametric statistical analysis. The calculations justified the results of examinations. Fig. 7 shows the values of measured and simulated velocity distribution in the course of peak hours traffic flows.

\section{The Problem of the Design of the Turn Left Lanes}

Üllöi Road-Ferenc Boulevard junction was examined. In the regard of safety the simplest method is that, if we stop all of the left turning possibility. In this case the vehicles may achieve adequate course with turning right three times on the side streets. Currently two lanes insure the possibility of turning left in this junction, which

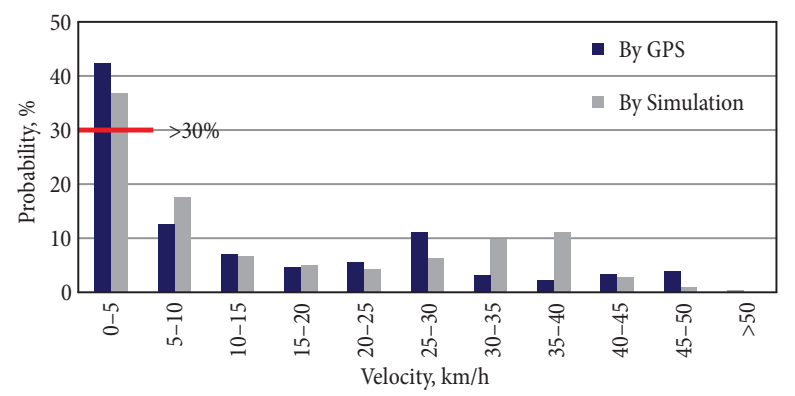

Fig. 7. The example of velocity distribution (source: own elaboration) manages considerable capacity, like this the traffic flow into the side streets may cause bigger congestions, than without the application of a reversible lane. Additionally the eventuality of the left turning was examined. On Fig. 8 the morning, on Fig. 9 the afternoon arrangement is visible, as it is typical of the full section, the afternoon design is equal to the present one.

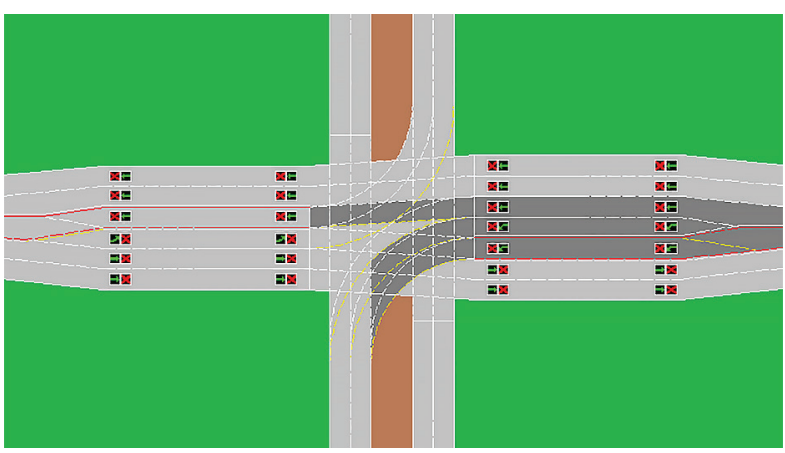

Fig. 8. The morning arrangement (source: own elaboration)

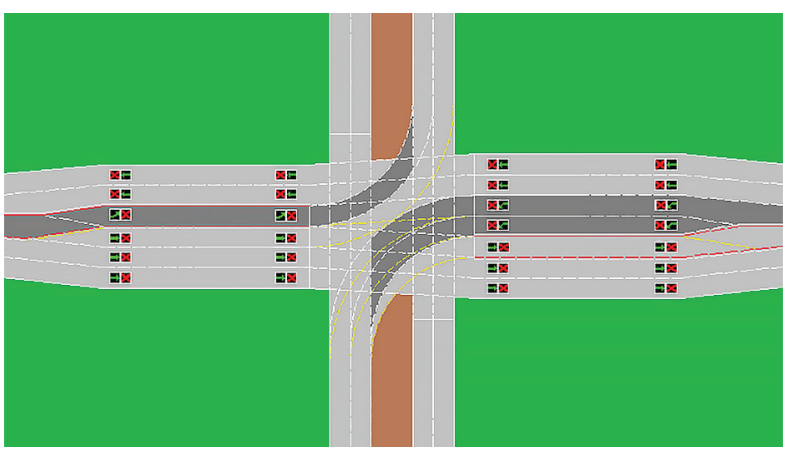

Fig. 9. The afternoon arrangement (source: own elaboration) 
The reversible lane is marked with red. This solution may proceed on 3-lanes towards the city centre and it may turn left on 2-lanes in the morning. It does not change the geometry size of the junction, on the other hand - it is not necessary to pay attention to the direction of only one lane, but it must adequately signal the progressing direction in the certain directions with Variable Message Signs (VMS) and LED pavement signals. The external left turn lane of the original arrangement will be the new straight lane and the lane taken away from the opposite direction will be the inner turn lane.

\section{Conclusions}

A general mathematical model describing the Reversible Lane System (RLS) was examined.

The descriptive mathematical network model is a positive NL dynamic system, and also important that it is a macroscopic model.

The function of every element and the contacts between the elements cease in case of direction change in any part of the network, then new contacts and new functional elements are activated.

The availability of the optimal control was examined in a sample network depending on the traffic density, using a new principle, which responses to the dynamic change of the structure of the network graph.

It can be shown, that the results from the model are in harmony with the real traffic values based on measurements made in road traffic systems working with RLS, included in the literature references.

\section{Acknowledgments}

The project presented in this article is supported by OTKA CNK 78168.

This work is connected to the scientific program of the 'Development of quality-oriented and harmonized $\mathrm{R}+\mathrm{D}+\mathrm{I}$ strategy and functional model at BME' project. This project is supported by the New Széchenyi Plan (Project ID: TÁMOP-4.2.1/B-09/1/KMR-2010-0002).

The work reported in the paper has been developed in the framework of the project 'Talent care and cultivation in the scientific workshops of BME' project. This project is supported by the grant TÁMOP4.2.2.B-10/1-2010-0009.

\section{References}

Bacciotti, A. 1983. On the positive orthant controllability of two-dimensional bilinear systems, Systems \& Control Letters 3(1): 53-55. http://dx.doi.org/10.1016/0167-6911(83)90038-5

Bede, Z.; Péter, T. 2010. The extraction of unique velocity processes from a macro model, Periodica Polytechnica: Transportation Engineering 38(2): 105-111. http://dx.doi.org/10.3311/pp.tr.2010-2.08

Bede, Z.; Szabó, G.; Péter, T. 2010. Optimalization of road traffic with the applied of reversible direction lanes, Periodica Polytechnica: Transportation Engineering 38(1): 3-8. http://dx.doi.org/10.3311/pp.tr.2010-1.01
Berta, T.; Török, Á. 2010. Travel time reduction due to infrastructure development in Hungary, Promet - Traffic \& Transportation 22(1): 23-27. http://dx.doi.org/10.7307/ptt.v22i1.161

Boothby, W. M. 1982. Some comments on positive orthant controllability of bilinear systems, SIAM Journal on Control and Optimization 20(5): 634-644. http://dx.doi.org/10.1137/0320047

Caccetta, L.; Rumchev, V. G. 2000. A survey of reachability and controllability for positive linear systems, Annals of Operations Research 98(1-4): 101-122. http://dx.doi.org/10.1023/A:1019244121533

Coxson, P. G.; Shapiro, H. 1987. Positive input reachability and controllability of positive systems, Linear Algebra and its Applications 94: 35-53. http://dx.doi.org/10.1016/0024-3795(87)90076-0

Čygas, D.; Jasiūnienè, V.; Bartkevičius, M. 2009. Assessment of special plans and technical designs with regard to traffic safety, Journal of Civil Engineering and Management 15(4): 411418. http://dx.doi.org/10.3846/1392-3730.2009.15.411-418

Farina, L.; Rinaldi, S. 2000. Positive Linear Systems: Theory and Applications. Wiley-Interscience. 318 p.

Luenberger, D. G. 1979. Introduction to Dynamic Systems: Theory, Models, and Applications. Wiley. 464 p.

Peter, T.; Basset, M. 2009. Application of new traffic models for determine optimal trajectories, in Proceedings of the 2009 International Forum on Strategic Technologies (IFOST 2009), 21-23 October 2009, Hochiminh City, Vietnam, 89-94.

Peter, T.; Bokor, J. 2011. New road traffic networks models for control, GSTF Journal on Computing $\left(J^{\circ} \mathrm{C}\right)$ 1(2): 227-232. http://dx.doi.org/10.5176/2010-2283_1.2.65

Peter, T.; Bokor, J. 2010. Modeling road traffic networks for control, in Proceedings of the Annual International Conference on Network Technologies \& Communications (NT\&C 2010), 29-30 November 2010, Phuket, Thailand, 18-22.

Péter, T.; Fülep, T.; Bede, Z. 2011. The application of a new principled optimal control for the dynamic change of the road network graph structure and the analysis of risk factors, in Complete Proceedings from the 13th EAEC European Automotive Congress 2011, 13-16 June 2011, Valencia, Spain (CD).

Sachkov, Y. L. 1997. On positive orthant controllability of bilinear systems in small codimensions, SIAM Journal on Control and Optimization 35(1): 29-35. http://dx.doi.org/10.1137/S0363012994270898

Valcher, M. E. 1996. Controllability and reachability criteria for discrete time positive systems, International Journal of Control 65(3): 511-536. http://dx.doi.org/10.1080/00207179608921708

Wolshon, B.; Lambert, L. 2006. Reversible lane systems: synthesis of practice, Journal of Transportation Engineering 132(12): 933-944. http://dx.doi.org/10.1061/(ASCE)0733947X(2006)132:12(933) 